
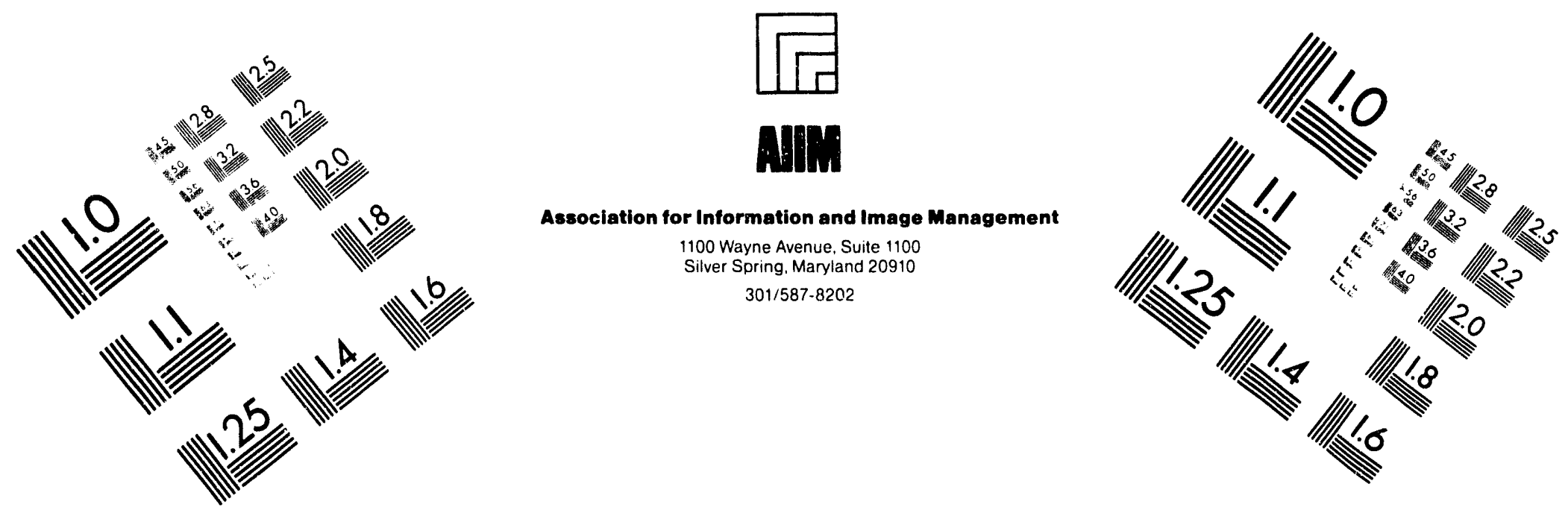

\title{
Centimeter
}

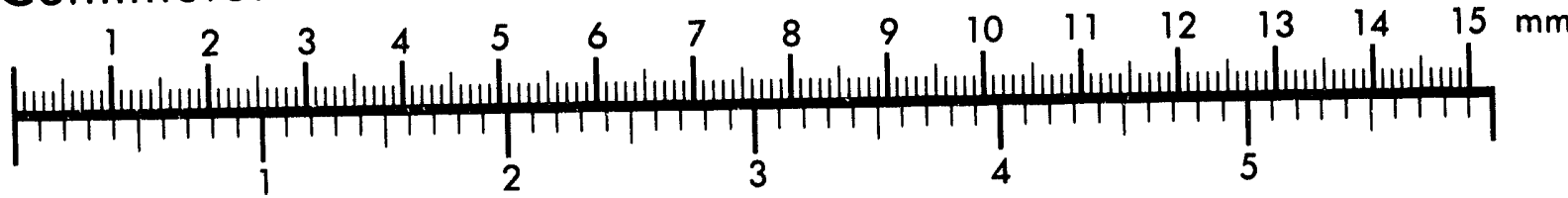
Inches
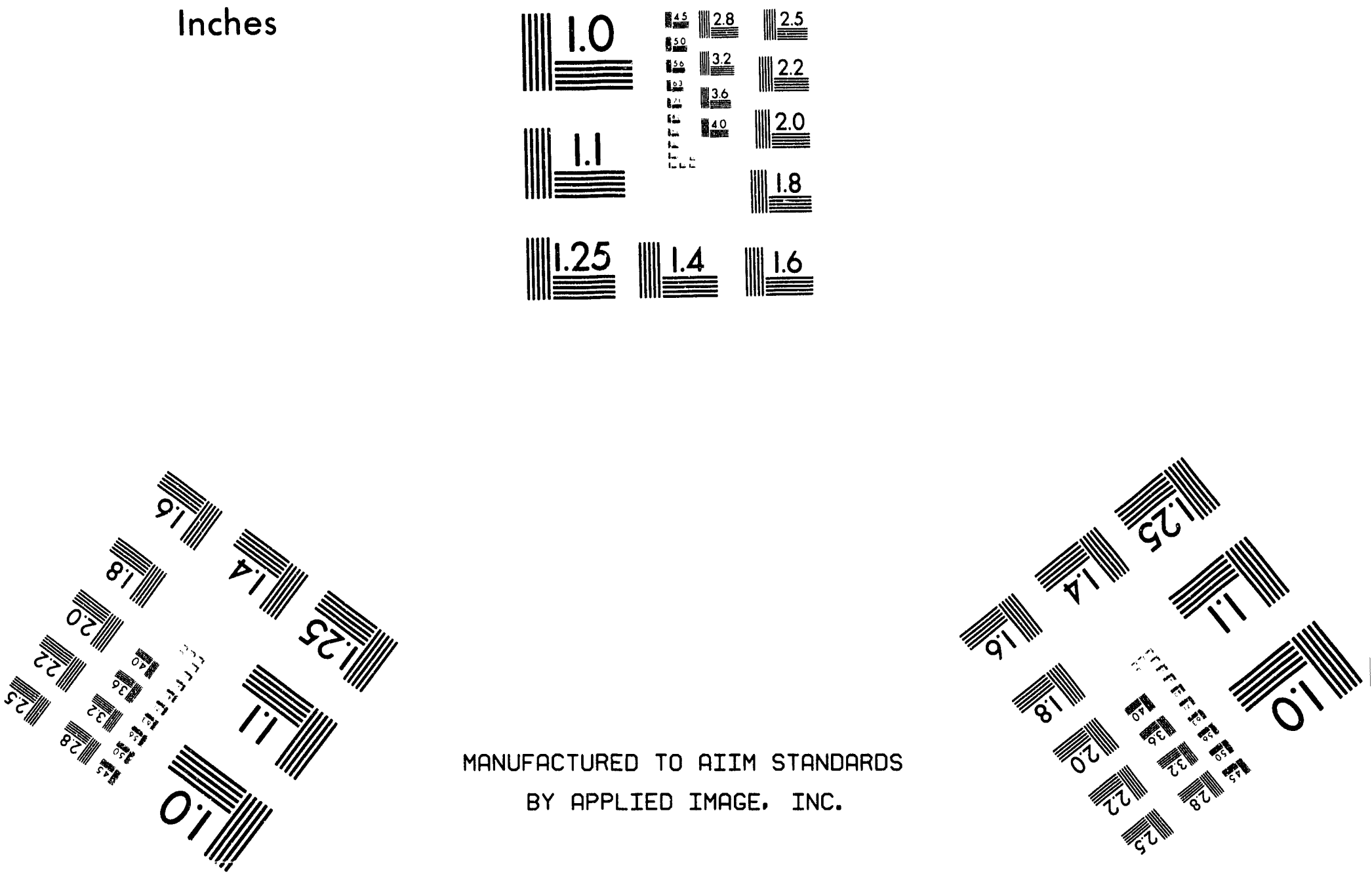

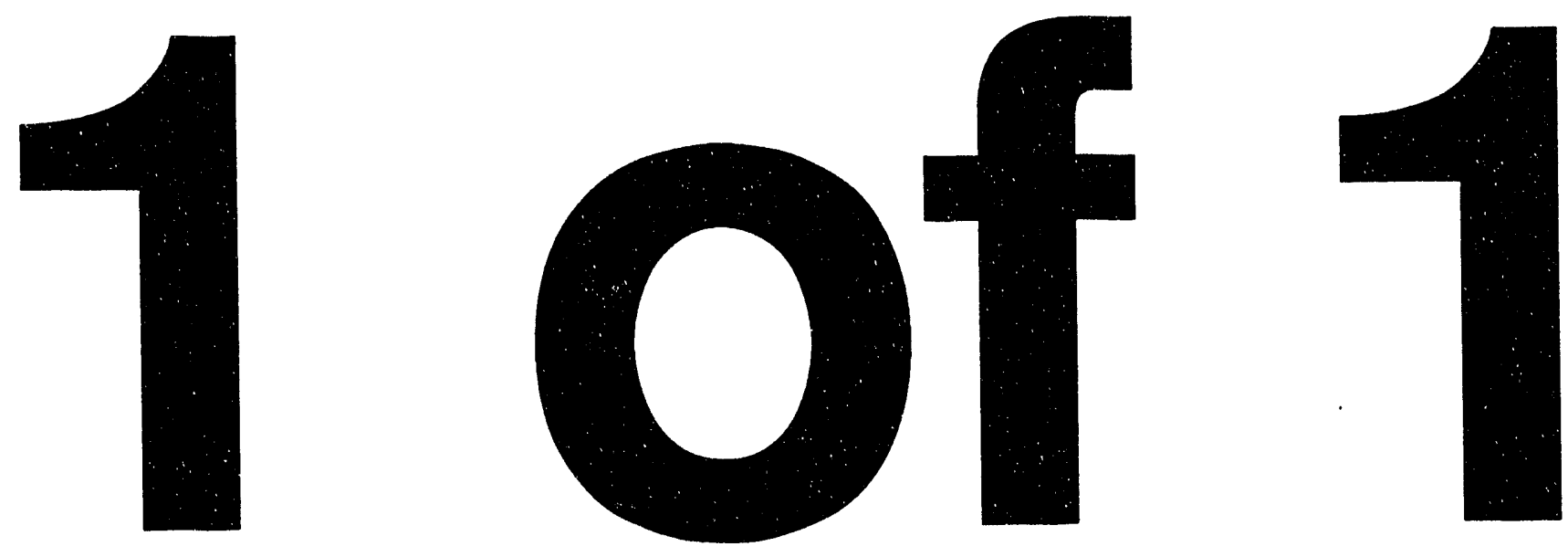


\title{
INFRARED SPECTROSCOPY OF ORGANIC FREE RADICALS RELATED TO COMBUSTION PROCESSES
}

(DE-FG02-92ER14306)

\author{
James C. Weisshaar \\ Department of Chemistry \\ University of Wisconsin-Madison \\ Madison, Wisconsin 53706-1396 \\ Internet: WEISSHAAR@CHEM.WISC.EDU
}

February 25, 1993

\section{Program Definition}

The primary long-term goal of this work is to develop new techniques for measuring vibrational spectra of polyatomic neutral free radicals. We will explore a variation of resonant two-photon ionization (R2PI) in which tunable $\omega_{I R}$ excites the radical vibrationally and $\omega_{U V}$ selectively ionizes only the vibrationally excited molecules. Development of the IR + UV R2PI experiment is underway. In the meantime, we have used optical R2PI and pulsed field ionization (PFI) detection to obtain new vibrational spectra of species such as the benzyl and phenylsilane cations. In benzyl, we have learned a great deal about the vibronic coupling mechanism in the mixed $1^{2} \mathrm{~A}_{2}-2^{2} \mathrm{~B}_{2}$ system near $450 \mathrm{~nm}$ by projecting the mixed states onto the manifold of cation vibrational states. In phenylsilane ${ }^{+}$, we find that the sixfold barrier to internal rotation of the silyl group is small $\left(\mathrm{V}_{6}=+19\right.$ $\left.\mathrm{cm}^{-1}\right)$. We are beginning to understand the mechanisms of coupling of torsional states with vibration, overall rotation, and other electronic states. In addition, we are developing a new model of internal rotation in aromatic compounds based on Prof. Frank Weinhold's natural resonance theory.

\section{Recent Progress}

\section{Benzyl Radical}

We create a skimmed beam of internally cold neutral benzyl radicals by $193 \mathrm{~nm}$ photolysis of toluene several $\mathrm{mm}$ downstream in a pulsed nozzle expansion. ${ }^{1}$ Internally cold benzyl radical is probed by two-color, resonant two-photon ionization (R2PI) through vibronically mixed $1^{2} \mathrm{~A}_{2}-2^{2} \mathrm{~B}_{2}$ excited states near $450 \mathrm{~nm} .{ }^{2,3,4}$ We obtain R2PI spectra of three isotopomers, benzyl ${ }^{+}-h_{7}$, benzyl ${ }^{+}-\alpha d_{2}$, and benzyl ${ }^{+}-d_{7}$. By tuning $\omega_{1}$ to a particular resonance, scanning $\omega_{2}$, and detecting electrons produced by delayed, pulsed field ionization (PFI), ${ }^{5}$ we obtain vibrational spectra of the corresponding cations primarily in the range $0-650 \mathrm{~cm}^{-1}$. We assign the low frequency bands by comparison with harmonic, normal mode frequencies from $a b$ initio calculations of the $\mathrm{X}^{1} \mathrm{~A}_{1}$ state of benzyl ${ }^{+}$.

The origin bands provide the following adiabatic ionization potentials: $58465 \pm 5 \mathrm{~cm}^{-1}=7.2487 \pm 0.0006 \mathrm{eV}$ for benzyl- $\mathrm{h}_{7} ; 58410 \pm 5 \mathrm{~cm}^{-1}$ for benzyl- $\alpha d_{2}$; and $58382 \pm 5 \mathrm{~cm}^{-1}$ for benzyl- $\mathrm{d}_{7}$. The benzyl-h $\mathrm{h}_{7}$ value 
refines our previous measurement ${ }^{6}$ of $58456 \pm 14 \mathrm{~cm}^{-1}$ from extrapolation of cation yield curves to zero field as well as the earlier value ${ }^{7}$ of $58100 \pm$ $160 \mathrm{~cm}^{-1}$. The accurate IP is important in thermochemical cycles.

In benzyl ${ }^{+}$, we observe several low-frequency vibrational states for each isotopomer. Table I collects the measured frequencies for all three isotopomers in the range $0-650 \mathrm{~cm}^{-1}$ and compares experiment with $a b$ initio calculations of harmonic frequencies. The vibronic mixing in the intermediate states ${ }^{8,9}$ allows us to observe benzyl ${ }^{+}$vibrational states of both $a_{1}$ and $b_{1}$ symmetry ( $C_{2 v}$ point group) in the PFI spectrum. The frequencies of the out-of-plane modes of benzyl ${ }^{+}$, which we obtain indirectly from combination bands and from $a b$ initio calculations, provide a quantitative measure of the bond order between the exocyclic $\mathrm{CH}_{2}$ group and the benzene ring. The cation clearly has substantially greater doublebond character than the neutral.

In addition, the intensities of the cation bands provide a measure of the vibrational character of the excited states of neutral benzyl, complementing recent dispersed fluorescence measurements. ${ }^{3 a}$ Our new data indicate that previous models ${ }^{8,9}$ of the vibronically mixed $1^{2} \mathrm{~A}_{2}-2^{2} \mathrm{~B}_{2}$ system have included unimportant modes and neglected important ones. In particular, certain low frequency combination states of overall $a_{1}$ or $b_{1}$ symmetry induce vibronic mixing efficiently.

Table I. Experimental and Calculated Vibrational Levels of $\mathrm{X}^{1} \mathrm{~A}_{1}$ State of Benzyl Cation. ${ }^{a}$

\begin{tabular}{|c|c|c|c|c|c|c|c|}
\hline \multirow[b]{2}{*}{ Level $^{b}$} & \multirow[b]{2}{*}{ symm } & \multicolumn{2}{|c|}{ benzyl $^{+}-\mathrm{h}_{7}$} & \multicolumn{2}{|c|}{ benzyl ${ }^{+}-\alpha d_{2}$} & \multicolumn{2}{|c|}{ benzyl $^{+}-d_{7}$} \\
\hline & & expt & calc & expt & calc & expt & calc \\
\hline$\nu_{36}+\nu_{17}$ & $b_{1}$ & 487 & 480 & 456 & 452 & 423 & 418 \\
\hline$\nu_{36}+\nu_{35}$ & $a_{1}$ & -- & 552 & - & 540 & 488 & 494 \\
\hline$\nu_{13}$ & $a_{1}$ & 526 & 537 & 504 & 524 & 500 & 511 \\
\hline$\nu_{28}$ & $b_{1}$ & 598 & 613 & 596 & 612 & 575 & 588 \\
\hline
\end{tabular}

${ }^{a}$ Calculated harmonic frequencies using Gaussian-90, MP2/6-31G*.

${ }^{\mathrm{b}}$ Approximate mode descriptions (op = out-of-plane, ip = in-plane): $\nu_{36}$

$=$ ring and $\mathrm{CH}_{2}$ op wag; $\nu_{35}=$ op $\mathrm{CH}$ ring wag; $\nu_{28}=$ ip ring deform;

$\nu_{17}=$ op ring $+\mathrm{CH}_{2}$ torsion; $\nu_{13}=$ ip CCC bend. 


\section{Phenylsilane}

Resonant two-photon ionization (R2PI) and pulsed field ionization (PFI) were used to measure $S_{1}-S_{0}$ and cation- $S_{1}$ spectra of phenylsilane cooled in a pulsed nozzle expansion. ${ }^{2}$ We obtain the adiabatic ionization potentials $\mathrm{IP}($ phenylsilane $)=73680 \pm 5 \mathrm{~cm}^{-1}, \mathrm{IP}($ phenylsilane $\cdot \mathrm{Ar})=73517 \pm 5$ $\mathrm{cm}^{-1}$ and IP(phenylsilane $\cdot \mathrm{Ar}_{2}$ ) $=73359 \pm 5 \mathrm{~cm}^{-1}$. We also resolve and assign many low lying torsion-vibration levels of the $S_{1}\left(X^{1} A_{1}\right)$ state of phenylsilane and of the $X^{2} B_{1}$ state of phenylsilane ${ }^{+}$. In both states, the pure torsional transitions are well fit by a simple sixfold hindered rotor Hamiltonian. The results for the rotor inertial constant $B$ and internal rotation potential barrier $V_{6}$ are: in $S_{1}, B=2.7 \pm 0.2 \mathrm{~cm}^{-1}$ and $V_{6}=-44$ $\pm 4 \mathrm{~cm}^{-1}$; in the cation, $B=2.7 \pm 0.2 \mathrm{~cm}^{-1}$ and $V_{6}=+19 \pm 3 \mathrm{~cm}^{-1}$. The sign of $\mathrm{V}_{6}$ and the conformation of minimum energy are inferred from spectral intensities of bands terminating at the $3 a_{1}$ " and $3 a_{2}$ " torsional levels. ${ }^{10,11}$ In $S_{1}$ the staggered conformation is most stable, while in the cation ground state the eclipsed conformation is most stable.

In phenylsilane ${ }^{+}$we find experimental evidence of coupling between torsion and vibration. ${ }^{12}$ For small $\mathrm{V}_{6}$, the term $\mathrm{P}_{\alpha} \mathrm{P}_{\mathrm{a}}$ in the rigid-frame model Hamiltonian strongly mixes the $6 a_{1}{ }^{\prime}$ and $6 a_{2}{ }^{\prime}$ torsional states, which mediates further torsion-vibrational coupling. In addition, the cation $X^{2} \mathrm{~B}_{1}$ vibrational structure is badly perturbed, apparently by strong vibronic coupling with the low-lying $A^{2} \mathrm{~A}_{2}$ state. Accordingly, our $a b$ initio calculations find a substantial in-plane distortion of the equilibrium geometry of the $X^{2} \mathrm{~B}_{1}$ state, while the $A^{2} \mathrm{~A}_{2}$ state is planar and symmetric.

For all sixfold potentials whose absolute phase is known experimentally, the most stable conformer is staggered in the neutral states $\left(S_{0}\right.$ and $S_{1}$ $p$-fluorotoluene, $S_{1}$ toluene, $S_{1} p$-fluorotoluene) ${ }^{10}$ and eclipsed in the cationic states (ground state toluene ${ }^{+11}$ and phenylsilane ${ }^{+12}$ ). We find that $a b$ initio calculations correctly predict the lowest energy conformer for $\mathrm{S}_{0}$ states and for cation ground states. In addition, we adapt the natural resonance theory (NRT) of Glendening and Weinhold ${ }^{13}$ to explain why sixfold barriers for methyl and silyl rotors are uniformly small, while some threefold barriers are quite large. The phase of the sixfold potential is apparently determined by a subtle competition between two types of rotorring potential terms: attractive donor-acceptor interactions and repulsive van der Waals interactions (steric effects). ${ }^{14}$

\section{Future Plans}

We have obtained high quality PFI spectra of the cations toluene ${ }^{+} \cdot \mathrm{Ar}$, $p$-fluorotoluene ${ }^{+}, p$-fluorotoluene ${ }^{+} \cdot$ Ar, and phenylsilane $^{+} \cdot$ Ar. Analysis of the data will provide a detailed picture of the interaction between the two low frequency motions: van der Waals bending and internal rotation of the methyl or silyl group.

In collaboration with Prof. Frank Weinhold, we have carried out high quality $a b$ initio calculations of the equilibrium geometries and vibrational frequencies of toluene $\left(S_{0}\right)$, toluene ${ }^{+}$, and many related molecules with sixfold and threefold symmetric torsional potentials. We plan to use the 
natural resonance theory to try to understand the underlying electronic factors that dictate the widely varying magnitudes of threefold potentials.

\section{References}

${ }^{1}$ G.C. Eiden, F. Weinhold, and J.C. Weisshaar, J. Chem. Phys. 95, 8665 (1991); ${ }^{* * G . C . ~ E i d e n ~ a n d ~ J . C . ~ W e i s s h a a r, ~ m a n u s c r i p t ~ i n ~ p r e p a r a t i o n . ~}$

${ }^{2}$ C. Cossart-Magos and S. Leach, J. Chem. Phys. 54, 1534 (1972); C. Cossart-Magos and W. Goetz, J. Mol. Spectrosc. 115, 366 (1986).

${ }^{3}$ a) M. Fukushima and K. Obi, J. Chem. Phys. 93, 8488 (1990). b) J. I. Selco and P. G. Carrick, J. Mol. Spectrosc. 137, 13 (1989).

${ }^{4}$ M. Heaven, L. Dimauro, and T. A. Miller, Chem. Phys. Lett. 95, 347 (1983).

${ }^{5}$ K. Müller-Dethlefs, and E.W. Schlag, Ann. Rev. Phys. Chem. 42, 109 (1991), and references therein.

${ }^{6}$ G.C. Eiden and J.C. Weisshaar, J. Phys. Chem. 95, 6194 (1991).

${ }^{7}$ F. A. Houle and J. L. Beauchamp, J. Am. Chem. Soc. 100, 3290 (1978).

${ }^{8}$ C. Cossart-Magos and S. Leach, J. Chem. Phys. 64, 4006 (1976).

${ }^{9}$ F. Negri, G. Orlandi, F. Zerbetto, and M. Z. Zgierski, J. Chem. Phys. 93, 600 (1990).

${ }^{10}$ A.-Q. Zhao, C.S. Parmenter, D.B. Moss, A.J. Bradley, A.E.W. Knight, and K.G. Owens, J. Chem. Phys. 96, 6362 (1992). Tables VI and VII summarize experimental knowledge of sixfold and threefold barriers to methyl group internal rotation.

${ }^{11}$ K.-T. Lu, G.C. Eiden, and J.C. Weisshaar, J. Phys. Chem. 96, 9742 (1992).

$12 * *$ K.-T. Lu and J.C. Weisshaar, J. Chem. Phys., submitted.

${ }^{13}$ E. Glendening, Ph.D. thesis, Dept. of Chemistry, Univ. of WisconsinMadison (1991); E. Glendening and F. A. Weinhold, work in progress.

${ }^{14}$ D.B. Moss, C.S. Parmenter, and G.E. Ewing, J. Chem. Phys. 86, 51 (1987); C.C. Martens and W.P., Reinhardt, J. Chem. Phys. 93, 5621 (1990).

** Work supported by DOE. 


\section{DISCLAIMER}

This report was prepared as an account of work spensored by an agency of the United States Goverumert. Neither the United States Goverameat nor any agency thereof. nor any of their employees, mikes any warranty, express or implied, or assumes any legal liability or responsibility for the acenracy, completeness, or usefulness of any information, apparatus, produch, or process disclosed, or represents that its use would not infringe privately owned rights. Reference herein to any specific commercial product, process, or service by trade name, tndemart, manufacturer. or otherwise does not necessarily constitute or imply its endorsement, recommendation, or favoring by the United States Government or any agency thereof. The views and opinions of authors expressed herein do not necesenrily state or reflect those of the United States Government or any ageacy thereof. 

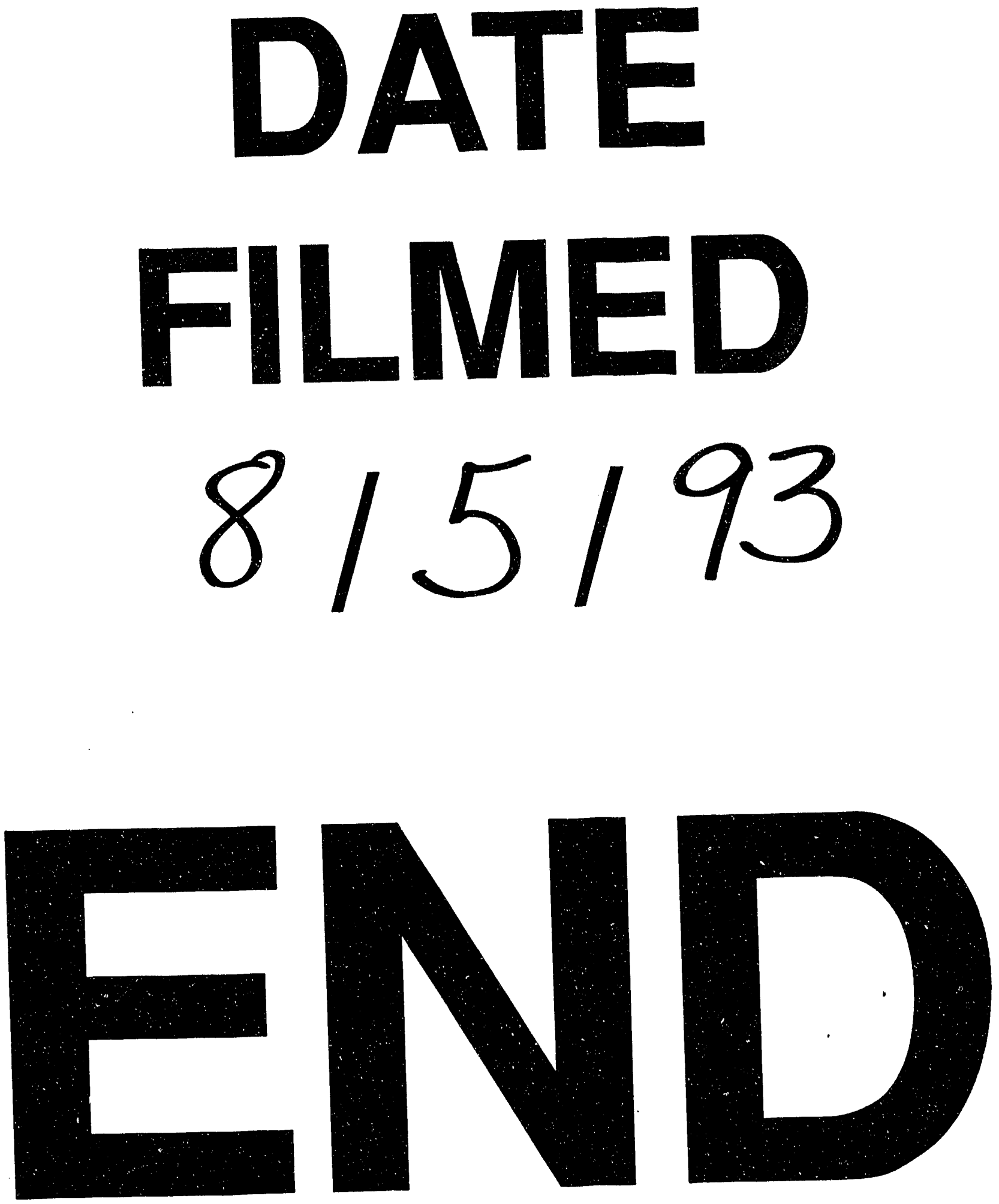


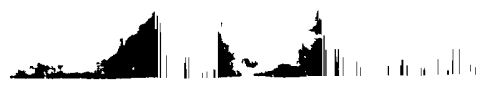

